\title{
Fluvoxamine in Treatment of Depression in Russian Patients: An Open-Label, Uncontrolled and Non-Randomized Multicenter Observational Study
}

\author{
Anatoly Boleslavovich Smulevich*, Natalia Alekseevna Ilyina, Victoria Valentinovna Chitlova \\ National Centre of Mental Health of the Russian Academy of Medical Sciences, Moscow, Russia \\ Email: ${ }^{*}$ absmulevich@list.ru
}

Received 20 July 2015; accepted 4 October 2015; published 7 October 2015

Copyright (C) 2015 by authors and Scientific Research Publishing Inc.

This work is licensed under the Creative Commons Attribution International License (CC BY). http://creativecommons.org/licenses/by/4.0/

(c) (i) Open Access

\section{Abstract}

Background: Fluvoxamine, a selective serotonin reuptake inhibitor is widely used in the treatment of depression, one of the most common disorders prevalent in Russia. However, studies demonstrating its efficacy and safety in routine settings in Russia are scarce. Methods: This prospective, uncontrolled, open-label study was conducted at 11 centers in Russia. Total 293 patients (aged $\geq 18$ years), meeting DSM-IV criteria for depression and scoring $\geq 17$ on 17-item Hamilton Rating Scale of Depression (HAMD-17) received fluvoxamine 50 - 300 mg for 6 weeks. Primary efficacy measures included change from baseline in the HAMD-17 and Clinical Global Impression (CGI) scores. Secondary efficacy measure was evaluation of sleep quality changes on HAMD-17 subscale. Safety was assessed by monitoring of adverse drug reactions (ADRs). Results: Mean age of patients was 42.7 years and the majority of them were women (72\%). At the end of treatment (day 42), clinically significant reduction was observed in mean HAMD-17, CGI-severity of illness and HAMD-17 sleep sub-score from 23.1, 4.5 and 3.9 at baseline to day 42; change from baseline $(\Delta)$ was: $\Delta-17.3$ [95\% CI: $-18.0 ;-16.7]$ ], $\Delta-2.1$ and $\Delta-3.4$ [95\% CI: $-3.53 ;-3.20]$ ], respectively. At day $42,20.8 \%$ patients reported as normal (not at all ill) on the CGI-severity scale and 85\% patients reported as "much improved" or "very much improved" on the CGI-change in severity and quality of life scores. Nausea $(12.6 \%)$ and somnolence $(5.1 \%)$ were the most frequently reported ADRs. No deaths or serious ADRs were reported but eight patients discontinued treatment due to ADRs. Conclusion: Treatment with fluvoxamine under routine settings showed marked improvement in Russian patients with depression as measured by HAMD-17 and CGI ratings and was thus efficacious as well as safe and well-tolerated.

${ }^{*}$ Corresponding author.

How to cite this paper: Smulevich, A.B., Ilyina, N.A. and Chitlova, V.V. (2015) Fluvoxamine in Treatment of Depression in Russian Patients: An Open-Label, Uncontrolled and Non-Randomized Multicenter Observational Study. Open Journal of Psychiatry, 5, 320-329. http://dx.doi.org/10.4236/ojpsych.2015.54036 


\section{Keywords}

\section{Fluvoxamine, Depression, Hamilton Rating Scale of Depression, Routine Settings}

\section{Introduction}

Depression is a complex mental disorder having a long-term negative impact on the health and economic well-being of both individuals and society. Globally, it affects more than 350 million people annually [1] with life time prevalence rates in general population ranging from $10 \%$ to $15 \%$ [2]. It is projected that by the year 2020 it will rank second for the Disability Adjusted Life Years calculated for all ages [3].

The scenario is similar in Russia where recent studies have indicated the prevalence of lifetime and current depressive disorders to be $30 \%$ and $20.7 \%$, respectively [4] with high percentages in both women (44\%) and men (23\%) [5]. Biochemical, endocrinal, neurophysiological, psychological and social-economical factors are known to play a role in the aetiology of depression. Social circumstances in particular, have a strong influence in increasing human depressive symptoms [6]. This is particularly evident in Russia, where social upheaval over a last few decades have led to high psychological distress and increased incidence of depression and related disorders [5]. Depressive disorders in general population needs immediate attention as it reduces a person's social functioning, ability to work and have a negative impact on the physical health and quality of life [7]. Moreover, its presence as a comorbid medical illness [8] with other prevalent psychotic disorders in Russia such as schizophrenia [9] raises concern as it usually tends to emerge in the form of psychogenic disorders and worsens the course of the primary disease [10]. A high quality of care for patients with depression in primary care settings is, therefore needed in order to minimize the morbidity caused by such a prevalent condition.

Various antidepressants currently dominate the medical management of depressive disorders and amongst different classes (e.g. tricyclic antidepressants [TCA], monoamine oxidase inhibitors, etc.), selective serotonin reuptake inhibitors (SSRIs) are recommended for wider usage around the world [11] [12]. The SSRIs act by selectively inhibiting the reuptake of neurotransmitter serotonin, which improves the transmission of neural signals, thereby reducing depressive symptoms and elevating the state of mind [12]. They are equivalent to TCAs in terms of efficacy, but score better on safety and tolerability [13]. National Institute for Health and Clinical Excellence recommends the use SSRI in generic form after considering potential side effects and patient preferences [14].

Among SSRIs, fluvoxamine is approved for the treatment of depression in many countries [15]. It has suitable pharmacokinetics that supports once-daily dosing [16] and has shown greater therapeutic benefit when compared with imipramine in patients with severe depression [17] [18]. Treatment with fluvoxamine is also associated with improvement in sleep quality [19] and has a lower impact on body weight [20].

Although fluvoxamine-based treatment is widely used for the management of depressive disorders in Russia, there are limited efficacy trials that are conducted in carefully selected populations under controlled conditions [4] [21]-[23]. Information on its efficacy and safety in treating depression under routine, uncontrolled settings, which is intended to have a greater generalizability in Russian population, is scarce. As a part of post-marketing surveillance, the present uncontrolled, multicenter, observational study was conducted to evaluate the efficacy and safety of fluvoxamine-based treatment for management of patients with depression under routine settings in Russia.

\section{Methods}

\subsection{Study Design}

This was an open label, observational study conducted at 11 centers in Russia from November 2006 to May 2007. Eligible patients received fluvoxamine 50 - 300 mg once-daily for 6 weeks with study visits scheduled on day 1, 7, 14, 28 and 42 (Figure 1). The recommended starting dose was 50 to $100 \mathrm{mg}$ once-daily and if necessary, the dose was increased by $50 \mathrm{mg}$ weekly up to a maximum of $300 \mathrm{mg} /$ day according to the patient's response and was divided in those receiving $>150 \mathrm{mg} /$ day.

The study was conducted in accordance with the ethical principles originating in the Declaration of Helsinki 


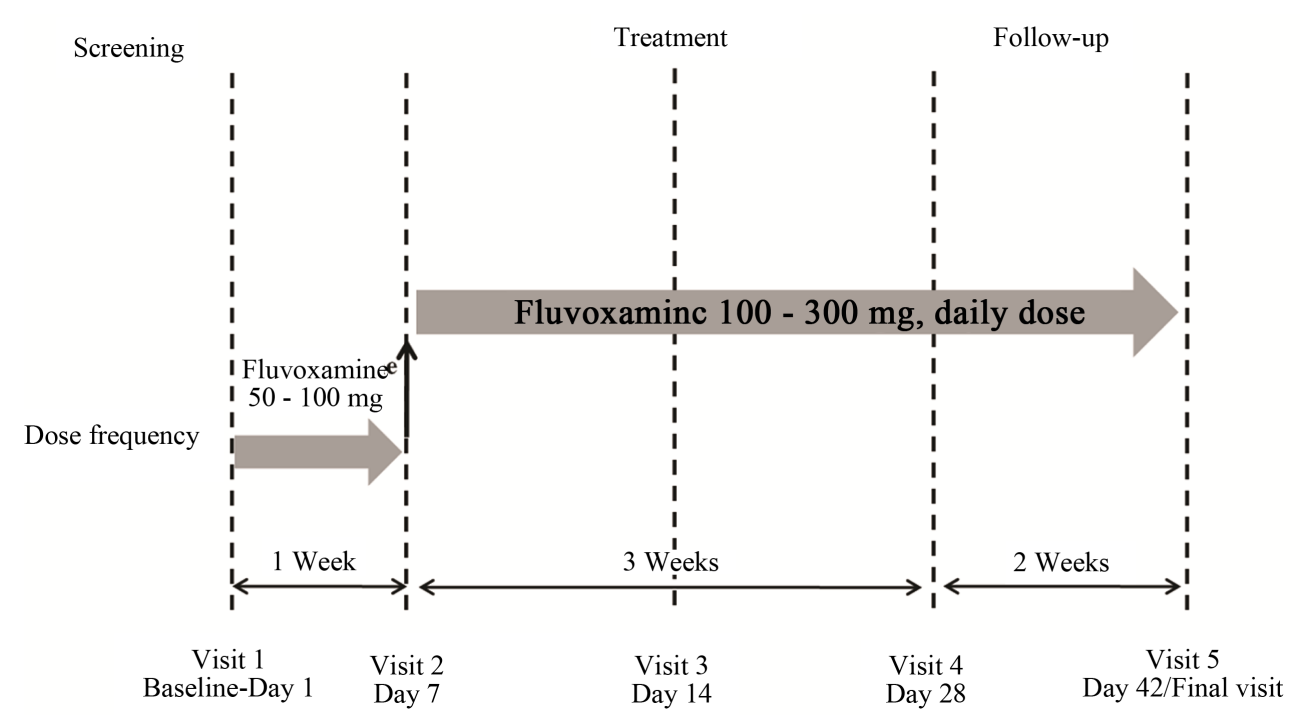

Figure 1. Study design.

and European Good Clinical Practice guidelines, applicable regulatory requirements, and in compliance with the protocol.

\subsection{Patients}

Adult male or female outpatients of 18 years of age and above with established depression, and who fulfilled the diagnostic criteria defined by the Diagnostic and Statistical Manual of Mental Disorders, 4th edition (DSM-IV) and had a score $\geq 17$ on the 17-item Hamilton Rating Scale of Depression (HAMD-17) were included in the study.

Patients with proven hepatic or renal insufficiency and those hypersensitive to the drug were excluded from the study. Other exclusion criteria included treatment with tizanidine or irreversible monoamine oxidase inhibitors within two weeks prior to baseline visit as well as pregnant or lactating women. Various classes of drugs that were not allowed during the surveillance period of the study included; antidepressants other than fluvoxamine, sedatives, tranquillizers, neuroleptics, antipsychotics, narcotics, anticonvulsants, anticoagulants and drugs like cisapride, propranolol, theophylline, cyclosporine, methadone, mexiletine, tacrine, metoprolol, terfenadine and astemizole. All patients were free to withdraw their participation in the study at any time.

\subsection{Efficacy Assessments}

The primary efficacy end points were the change from baseline in HAMD-17 total score and Clinical Global Impression (CGI). The HAMD-17 total scores were assessed at baseline and study days 7, 14, 28 and day 42 (or upon early withdrawal from the study), while CGI was recorded at baseline and day 42.

The secondary efficacy end point was the change from baseline in the sleep quality as assessed by items 4,5 and 6 of the HAMD-17 over the six-week period.

\subsection{Safety Assessments}

Tolerability and safety were assessed through collection and monitoring of any spontaneously reported adverse drug reactions (ADRs), serious ADRs, and physical examination (height and weight). All concomitant medications were also reviewed and vital characteristics such as systolic blood pressure (SBP), diastolic blood pressure (DBP), and pulse rate were measured at baseline and day 42.

\subsection{Statistical Analysis}

No formal sample size calculation was done. Based on the feasibility, a total number of 300 patients were considered adequate to collect considerable exposure of fluvoxamine. Safety analysis was performed on all patients 
who received at least one dose of study medication (safety population), whereas efficacy analysis was performed on all patients who were included in the safety sample and had at least one post-baseline assessment of any efficacy measurement (ITT population).

Descriptive statistics were used to summarize the demographic variables. Changes from baseline for all efficacy measures were presented by descriptive statistics, including 95\% confidence intervals (CIs) and one-sample t-test. Endpoint refers to the last non-missing observation during a post-baseline visit.

Safety was assessed primarily by reporting of ADR. All reported treatment-emergent ADRs were taken into account, coded according to Medical Dictionary for Regulatory Activities (MedDRA) and presented in summary tables with the number and percentage of patients who reported that ADR.

\section{Results}

\subsection{Patient Disposition, Baseline Demographics and Clinical Characteristics}

A total of 293 patients were recruited and treated with fluvoxamine. Total 15 patients withdrew before completion of the six weeks of treatment, reasons were: ADRs ( $n=8$; nausea being the most frequent $[n=3])$, lack of efficacy $(n=3)$, loss to follow-up $(n=2)$ and withdrawal of consent $(n=2)$. No clinically relevant protocol deviations were observed during the study.

The patient's baseline characteristics are listed in Table 1 . The mean age was 42.7 years with body mass index

Table 1. Patient baseline demographics and clinical characteristics.

\begin{tabular}{|c|c|}
\hline Parameter & Value \\
\hline $\begin{array}{l}\text { Age (years) } \\
\mathrm{N} \\
\text { Mean (SD) }\end{array}$ & $\begin{array}{c}293 \\
42.7(13.9)\end{array}$ \\
\hline $\begin{array}{l}\text { Age category (years), n (\%) } \\
\begin{array}{c}17-29 \\
30-49 \\
50-64 \\
\geq 65\end{array}\end{array}$ & $\begin{array}{c}59(20.1) \\
138(47.1) \\
76(25.9) \\
20(6.8)\end{array}$ \\
\hline $\begin{array}{l}\text { Sex, } n(\%) \\
\text { Men } \\
\text { Women }\end{array}$ & $\begin{array}{c}81(27.6) \\
212(72.4)\end{array}$ \\
\hline $\begin{array}{c}\text { Height }(\mathrm{cm}) \\
\mathrm{n} \\
\text { Mean }(\mathrm{SD})\end{array}$ & $\begin{array}{c}287 \\
168.0(8.6)\end{array}$ \\
\hline $\begin{array}{c}\text { Weight (kg) } \\
n \\
\text { Mean (SD) }\end{array}$ & $\begin{array}{c}292 \\
70.2(13.6)\end{array}$ \\
\hline $\begin{array}{c}\text { Body Mass Index }\left(\mathrm{Kg} / \mathrm{m}^{2}\right) \\
\mathrm{n} \\
\text { Mean (SD) }\end{array}$ & $\begin{array}{c}287 \\
24.9(4.2)\end{array}$ \\
\hline $\begin{array}{c}\text { Diastolic Blood Pressure (mmHg) } \\
\text { n } \\
\text { Mean (SD) }\end{array}$ & $\begin{array}{c}292 \\
78.0(9.1)\end{array}$ \\
\hline $\begin{array}{c}\text { Systolic Blood Pressure (mmHg) } \\
\text { n } \\
\text { Mean (SD) }\end{array}$ & $\begin{array}{c}292 \\
123.0(13.5)\end{array}$ \\
\hline $\begin{array}{c}\text { HAMD-17 Total Score } \\
\text { n } \\
\text { Mean (SD) }\end{array}$ & $\begin{array}{c}293 \\
23.1(4.6)\end{array}$ \\
\hline $\begin{array}{c}\text { CGI-S } \\
n \\
\text { Mean (SD) }\end{array}$ & $\begin{array}{c}293 \\
4.5(0.8)\end{array}$ \\
\hline $\begin{array}{c}\text { HAMD-17 Sleep Sub-score } \\
\mathrm{n} \\
\text { Mean (SD) }\end{array}$ & $\begin{array}{c}293 \\
3.9(1.3)\end{array}$ \\
\hline
\end{tabular}

CGI-S: Clinical Global Impression Severity, HAMD-17: 17-item Hamilton Rating Scale of Depression, SD: standard deviation. 
(BMI) of $24.9 \mathrm{~kg} / \mathrm{m}^{2}$ and majority of them were women (72\%). The most frequently reported pre-existing medical conditions were cardiovascular diseases (15\%), cranial trauma (13.0\%) and psychiatric disorders other than depression (9.9\%). Drug/alcohol abuse was recorded in nine patients (3.1\%).

The most frequently prescribed concomitant medications were sedatives $(23.9 \%)$, cardiovascular drugs (12.6\%), anti-epileptic drugs (9.6\%) and antipsychotics (9.6\%). Antidepressant combination therapy was prescribed for seven patients (2.4\%).

\subsection{Efficacy Variables}

\subsubsection{HAMD-17 Total Score}

A visit-wise plot of mean change in HAMD-17 total score is presented in Figure 2. At baseline, the mean ( $\pm \mathrm{SD}$ ) total HAMD-17 score was $23.1 \pm 4.6$ and decreased steadily over time and improved to $5.8 \pm 4.3$ at the final visit on day 42 (change from baseline $\Delta[95 \% \mathrm{CI}]:-17.3[-18.0 ;-16.7]$ ). Overall, a reduction of $74.89 \%$ was observed in the mean scores of HAMD-17 from baseline to the final visit on day 42.

\subsubsection{HAMD-17 Sleep Sub-Score}

The mean $( \pm \mathrm{SD})$ HAMD-17 sleep sub-score decreased from $3.9 \pm 1.3$ at baseline to $0.6 \pm 0.8$ at the final visit on day 42 (change from baseline $\Delta[95 \% \mathrm{CI}]$ : $-3.4[-3.53$; -3.20$]$ ). At endpoint, the mean score was $0.7 \pm 1.0$ (Figure 3).

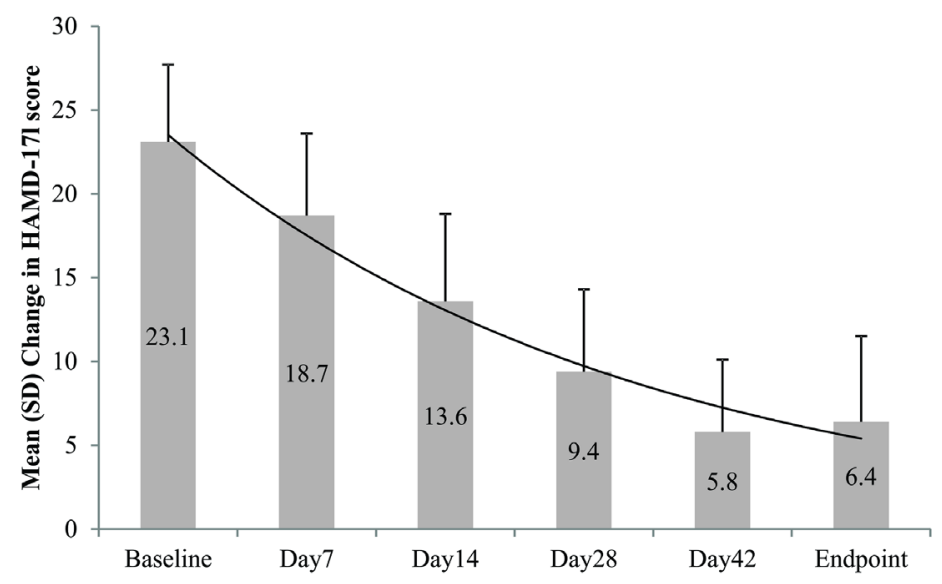

Figure 2. Change from baseline to day 42 in HAMD-17 total score (intent-to-treat analysis set) HAMD-17: 17-item Hamilton Rating Scale of Depression.

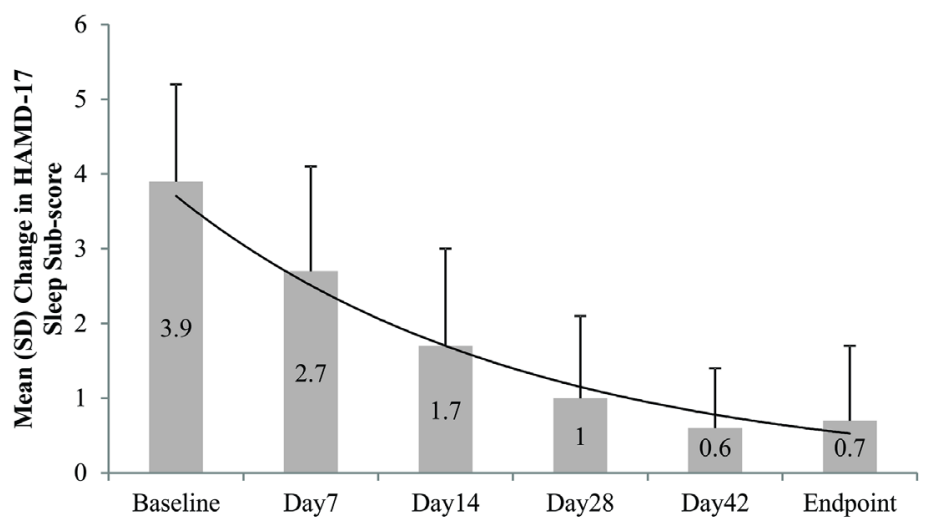

Figure 3. Changes from baseline to day 42 in the HAMD-17 sleep subscore (intent-to-treat analysis set) HAMD-17: 17-item Hamilton Rating Scale of Depression. 


\subsubsection{CGI Scores}

The mean CGI-severity score decreased from 4.5 (moderately to markedly ill) at baseline to 2.4 (borderline to mildly ill) on day 42 . Overall, a reduction of $46.67 \%$ was recorded in the mean CGI-scores at the end of treatment (day 42). More than $85 \%$ of patients were reported as "much improved" or "very much improved" as per the CGI-change in severity and quality of life scores at day 42 (Figure 4).

At the end of treatment (day 42), 20.8\% patients $(n=58)$ were reported as normal (not at all ill) on the CGIseverity scale by the investigator. There was a substantial improvement in patient's clinical condition classified as "borderline mentally ill” when compared to baseline in this category ( $40.9 \%$ vs $0.7 \%$ ) (Table 2). The majority of patients and investigators rated the treatment as good (66.67\%) to excellent (20\% - 21\%).

\subsection{Safety and Tolerability}

A total of 72 patients (24.6\%) experienced at least one ADR during the six-week period (Table 3). The majority of ADRs were mild or moderate in severity. Nausea $(37,12.6 \%)$ and somnolence $(15,5.1 \%)$ were the most frequently reported ADRs. No deaths and serious ADRs were reported, but eight patients discontinued treatment

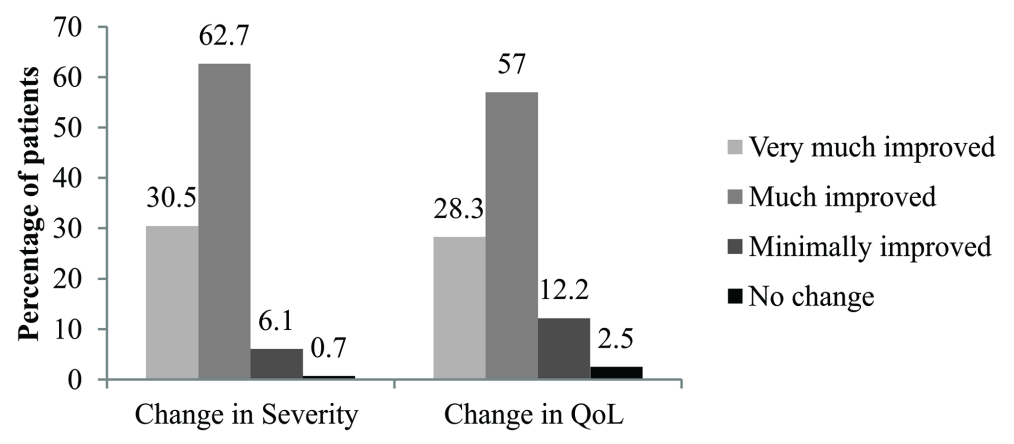

Figure 4. CGI per classifications of change in severity and change in QoL (intent-to-treat analysis set) CGI: Clinical Global Impression, QoL: Quality of Life.

Table 2. CGI-S classification at baseline and day 42 (intent-to-treat analysis set).

\begin{tabular}{ccc}
\hline Severity & Baseline $\mathrm{n}(\%)$ & Day $42 \mathrm{n}(\%)$ \\
\hline Normal, not at all ill & $0(0.0)$ & $58(20.8)$ \\
Borderline mentally ill & $2(0.7)$ & $114(40.9)$ \\
Mildly ill & $19(6.5)$ & $67(24.0)$ \\
Moderately ill & $140(47.8)$ & $30(10.8)$ \\
Markedly ill & $102(34.8)$ & $9(3.2)$ \\
Severely ill & $29(9.9)$ & $1(0.4)$ \\
Most extremely ill & $1(0.3)$ & $0(0.0)$ \\
\hline
\end{tabular}

CGI-S: Clinical Global Impression Severity.

Table 3. Adverse events reported in $>1 \%$ of patients (Safety analysis set) (order of frequency).

\begin{tabular}{cc}
\hline Adverse Drug Reaction (ADR) & $\mathrm{n}(\%)$ \\
\hline Patients with $\geq 1$ ADR & $72(24.6)$ \\
Nausea & $37(12.6)$ \\
Somnolence & $15(5.1)$ \\
Headache & $6(2.0)$ \\
Vertigo & $5(1.7)$ \\
Asthenia & $4(1.4)$ \\
Constipation & $4(1.4)$ \\
\hline
\end{tabular}


due to ADRs during the study. Nausea in two patients, sleepiness and diarrhea in one patient each were the only severe ADRs. No clinically significant changes were observed in vital signs, body weight, BMI, pulse rate, DBP, and SBP.

\section{Discussion}

Prevalence of depression in Russian population is substantial, but studies dealing with the treatment needs in this population under routine settings are limited. Although, fluvoxamine is the preferred line of treatment for depression, studies examining its effectiveness under daily practice from Russia are scarce. This observational study established the efficacy of fluvoxamine-based treatment as evidenced by a significant improvement in HAMD-17 total scores and CGI scores. To the best of our knowledge, this is the first open-label observational study to examine the efficacy and safety of fluvoxamine-based treatment in Russian patients with depression under uncontrolled routine settings.

The high percentage of female patients with depression (72\%) in this study is line with other published reports [24] [25] reporting high prevalence of depression in Russian females in comparison with the male population; similarly observed worldwide.

The efficacy results of this study are consistent with other studies using the same drug in populations from Europe and other regions [19] [26]-[28]. The observed 75\% reduction in the HAMD-17 score with fluvoxamine treatment is similar to the clinically significant change of 71\% recorded in another study [29].

Fluvoxamine in contrast to other anti-depressants is known to have an early onset of action, which is an important consideration as depressed patients are prone to harm themselves if not treated at an earlier stage. Early onset of action may also reduce the occurrence of treatment discontinuations, which may be due to lack of efficacy, one of the commonest factors seen in routine settings. Thus, decrease in HAMD-17 score as early as day 7 may explain why very few patients discontinued the treatment due to lack of efficacy [30]. These findings correlate with a double-blind study wherein fluvoxamine was reported to have a relatively faster onset of therapeutic action when compared with other SSRIs [19].

Similar to HAMD-17 total score, improvement was also noted in the CGI scores. A 46.67\% reduction in the mean CGI-severity scores was recorded at the endpoint and a total of $20.8 \%$ patients were categorized as being "normal” and "not at all ill”, as per the CGI-severity scale. Earlier studies have reported significantly more responders on the CGI-severity and a greater reduction of CGI-severity scores for fluvoxamine treatment when compared to other SSRIs at week 2, but not at week 4 or 6 [19]. As we only evaluated the CGI scores at baseline and week 6 (day 42), our study provides further evidence of a favorable response of fluvoxamine on CGI scores also at week 6.

Depression is associated with a poor quality of life [31]. This study showed improvement in quality of life of the patients over a 6-week treatment, which is in conformance with other studies [26] [32]. Improvements were also observed in quality of sleep, as measured by the HAMD-17 sleep sub-score and the results are in accordance with the previous studies [19] [33] where fluvoxamine treatment was shown to have a faster onset of action against depressive symptoms and better improvement in sleep quality as compared with other SSRIs.

Fluvoxamine treatment exhibited good safety and favorable tolerability profile in this study. Nausea and somnolence were the most commonly reported ADRs. These results are consistent with the previous studies [20] [34]-[36]. In this study, fluvoxamine treatment led to no remarkable changes in either body weight or BMI. These findings are highly encouraging in the treatment of depression as it enhances adherence and reduces noncompliance in patients requiring long-term treatment [20].

Although an open-label, uncontrolled study has its own limitations; the routine setting does provide a more realistic approximation of clinical practice when compared to a double-blind study. Limitation of the study was its short duration, which disallowed information about relapse and remission maintenance in patients with depression.

\section{Conclusion}

Treatment with fluvoxamine under routine settings showed marked improvement in Russian patients with depression as measured by HAMD-17 and CGI ratings and was thus efficacious as well as safe and well-tolerated. The lack of empirical evidence in the treatment of depression in primary care settings serves a major barrier in the management of depression. The routine setting of this study targets to fill this gap to some extent while vali- 
dating and extending the safety and efficacy of fluvoxamine treatment for depression in the Russian population.

\section{Acknowledgements}

The authors thank Dr. Khushboo Nagdev and Dr. Shirin Ghodke (SIRO Clinpharm Pvt. Ltd.) for providing writing assistance. The authors also thank the study participants, without whom this study would not have been accomplished.

\section{Conflict of Interest}

This study was funded by Solvay Pharmaceuticals, Russia.

\section{Disclosure}

All authors met ICMJE criteria and all those who fulfilled those criteria were listed as authors. All authors had access to the study data and made the final decision about where to present these data.

\section{References}

[1] World Health Organization. (2012) Depression a Global Public Health Concern. http://www.who.int/mental_health/management/depression/who_paper_depression_wfmh_2012.pdf

[2] Lépine, J.P. and Briley, M. (2011) The Increasing Burden of Depression. Journal of Neuropsychiatric Disease and Treatment, 7, 3-7.

[3] Reddy, M.S. (2010) Depression: The Disorder and the Burden. Indian Journal of Psychological Medicine, 32, 1-2. http://dx.doi.org/10.4103/0253-7176.70510

[4] Pakriev, S., Kovalev, J. and Mozhaev, M. (2009) Prevalence of Depression in a General Hospital in Izhevsk, Russia. Nordic Journal of Psychiatry, 63, 469-474. http://dx.doi.org/10.3109/08039480903062950

[5] Bobak, M., Pikhart, H., Pajak, A., Kubinova, R., Malyutina, S., Sebakova, H., et al. (2006) Depressive Symptoms in Urban Population Samples in Russia, Poland and the Czech Republic. The British Journal of Psychiatry, 188, 359-365. http://dx.doi.org/10.1192/bjp.188.4.359

[6] Nicholson, A., Pikhart, H., Pajak, A., Malyutina, S., Kubinova, R., Peasey, A., et al. (2008) Socio-economic Status over the Life-Course and Depressive Symptoms in Men and Women in Eastern Europe. Journal of Affective Disorders, 105, 125-136. http://dx.doi.org/10.1016/j.jad.2007.04.026

[7] Patel, D. (2008) Depression is the Most Common Mental Disorder in Community Settings, and Is a Major Cause of Disability. Occupational Medicine (London), 58, 453. http://dx.doi.org/10.1093/occmed/kqn135

[8] Gurovich, I.Y., Schmukler, A.B., Storozhakova, Y.A., Kiryanova, E.M., Salnikova, L.I., Gazha, A.K., et al. (2013) Depressive Symptoms Diagnosis and Treatment of Schizophrenia and Schizophrenia Spectrum Disorders in Russian Clinical Practice. Zhurnal Nevrologii i Psikhiatrii Imeni S.S. Korsakova, 113, 28-33.

[9] Smulevich, A.B., Drobizhev, M.A. and Ivanov, S.V. (2002) Schizophrenia and Schizophrenia Spectrum Disorders in General Hospital. Zhurnal Nevrologii i Psikhiatrii Imeni S.S. Korsakova, 102, 9-13.

[10] Smulevich, A.V. (2003) Depression and Schizophrenia. Zhurnal Nevrologii i Psikhiatrii Imeni S.S. Korsakova, 103, 4-13.

[11] Kozyrev, V.N., Smulevich, A.B., Drobizhev, M.I., Kraeva, G.K. and Kubrakov, M.A. (2003) Psychotropic Drugs Used in a Psychiatric Hospital (Pharmaco-Epidemiologic Aspects). Zhurnal Nevrologii i Psikhiatrii Imeni S.S. Korsakova, 103, 25-32.

[12] Gartlehner, G., Hansen, R.A., Thieda, P., De Veaugh-Geiss, A.M., Gaynes, B.N., Krebs, E.E., et al. (2007) Comparative Effectiveness of Second-Generation Antidepressants in the Pharmacologic Treatment of Adult Depression. Agency for Healthcare Research and Quality, Rockville. http://www.effectivehealthcare.ahrq.gov/repFiles/Antidepressants_Final_Report.pdf13

[13] von Wolff, A., Hölzel, L.P., Westphal, A., Härter, M. and Kriston, L. (2013) Selective Serotonin Reuptake Inhibitors and Tricyclic Antidepressants in the Acute Treatment of Chronic Depression and Dysthymia: A Systematic Review and Meta-Analysis. Journal of Affective Disorders, 144, 7-15. http://dx.doi.org/10.1016/j.jad.2012.06.007

[14] National Institute for Health and Clinical Excellence (2009) Depression: The Treatment and Management of Depression in Adults (Update). National Clinical Practice Guideline 90. http://www.nice.org.uk/nicemedia/pdf/CG90NICEguideline.pdf

[15] Hachisu, M. and Ichimaru, Y. (2000) Pharmacological and Clinical Aspects of Fluvoxamine (Depromel): The First Se- 
lective Serotonin Reuptake Inhibitor Approved for Clinical Use Employed in Japan. Folia Pharmacologica Japonica, 115, 271-279. http://dx.doi.org/10.1254/fpj.115.271

[16] Hrdina, P.D. (1991) Pharmacology of Serotonin Uptake Inhibitors: Focus on Fluvoxamine. Journal of Psychiatry \& Neuroscience, 16, 10-18.

[17] Fabre, L., Birkhimer, L.J., Zaborny, B.A., Wong, L.F. and Kapik, B.M. (1996) Fluvoxamine versus Imipramine and Placebo: A Double-Blind Comparison in Depressed Patients. International Clinical Psychopharmacology, 11, 119127.

[18] Kasper, S., Möller, H.J., Montgomery, S.A. and Zondag, E. (1995) Antidepressant Efficacy in Relation to Item Analysis and Severity of Depression: A Placebo-Controlled Trial of Fluvoxamine versus Imipramine. International Clinical Psychopharmacology, 9, 3-12. http://dx.doi.org/10.1097/00004850-199501004-00001

[19] Dalery, J. and Honig, A. (2003) Fluvoxamine versus Fluoxetine in Major Depressive Episode: A Double-Blind Randomized Comparison. Human Psychopharmacology, 18, 379-384. http://dx.doi.org/10.1002/hup.490

[20] Westenberg, H.G. and Sandner, C. (2006) Tolerability and Safety of Fluvoxamine and Other Antidepressants. International Journal of Clinical Practice, 60, 482-491. http://dx.doi.org/10.1111/j.1368-5031.2006.00865.x

[21] Panteleeva, G.P., Abramova, L.I. and Korenev, A.N. (2000) Selective Serotonin Reuptake Inhibitors in the Therapy of Various Types of Endogenous Depressions. Zhurnal nevrologii i psikhiatrii imeni S.S. Korsakova, 100, 36-41.

[22] Sheĭfer, M.S., Tsybina, M.I. and Davydenko, M.V. (2000) Fluvoxamine (Fevarin) in the Treatment of Depression. Zhurnal nevrologii i psikhiatrii imeni S.S. Korsakova, 100, 64-67.

[23] Neznamov, G.G., Siuniakov, S.A., Teleshova, E.S., Dorofeeva, O.A., Chumakov, D.B. and Davydova, I.A. (2001) Therapeutic Action and Efficiency of Fevarin (Fluvoxamine) in Patients with Non-Psychotic Anxious and ApathicAdynamic Depressions. Zhurnal nevrologii i psikhiatrii imeni S.S. Korsakova, 101, 19-24.

[24] Averina, M., Nilssen, O., Brenn, T., Brox, J., Arkhipovsky, V.L. and Kalinin, A.G. (2005) Social and Lifestyle Determinants of Depression, Anxiety, Sleeping Disorders and Self-Evaluated Quality of Life in Russia-A PopulationBased Study in Arkhangelsk. Social Psychiatry and Psychiatric Epidemiology, 40, 511-518. http://dx.doi.org/10.1007/s00127-005-0918-x

[25] Gafarov, V.V., Panov, D.O., Gromova, E.A., Gagulin, I.V. and Gafarova, A.V. (2013) The Influence of Depression on Risk Development of Acute Cardiovascular Diseases in the Female Population Aged 25 - 64 in Russia. International Journal of Circumpolar Health, 72. http://dx.doi.org/10.3402/ijch.v72i0.21223

[26] Sonawalla, S.B., Spillmann, M.K., Kolsky, A.R., Alpert, J.E., Nierenberg, A.A., Rosenbaum, J.F., et al. (1999) Efficacy of Fluvoxamine in the Treatment of Major Depression with Comorbid Anxiety Disorders. The Journal of Clinical Psychiatry, 60, 580-583. http://dx.doi.org/10.4088/JCP.v60n0903

[27] Furuse, T. and Hashimoto, K. (2009) Fluvoxamine Monotherapy for Psychotic Depression: The Potential Role of Sigma-1 Receptors. Annals of General Psychiatry, 8, 26. http://dx.doi.org/10.1186/1744-859x-8-26

[28] Kishimoto, A., Todani, A., Miura, J., Kitagaki, T. and Hashimoto, K. (2010) The Opposite Effects of Fluvoxamine and Sertraline in the Treatment of Psychotic Major Depression: A Case Report. Annals of General Psychiatry, 9, 23. http://dx.doi.org/10.1186/1744-859x-9-23

[29] Zohar, J., Keegstra, H. and Barrelet, L. (2003) Fluvoxamine as Effective as Clomipramine against Symptoms of Severe Depression: Results from a Multicentre, Double-Blind Study. Human Psychopharmacology, 18, 113-119. http://dx.doi.org/10.1002/hup.442

[30] Katoh, Y., Uchida, S., Kawai, M., Takei, N., Mori, N., Kawakami, J., et al. (2010) Onset of Clinical Effects and Plasma Concentration of Fluvoxamine in Japanese Patients. Biological \& Pharmaceutical Bulletin, 33, 1999-2002. http://dx.doi.org/10.1248/bpb.33.1999

[31] Rapaport, M.H., Clary, C., Fayyad, R. and Endicott, J. (2005) Quality-of-Life Impairment in Depressive and Anxiety Disorders. American Journal of Psychiatry, 162, 1171-1178. http://dx.doi.org/10.1176/appi.ajp.162.6.1171

[32] Stein, M., Fyer, A., Davidson, J., Pollack, M. and Wiita, B. (1999) Fluvoxamine Treatment of Social Phobia (Social Anxiety Disorder): A Double-Blind, Placebo-Controlled Study. American Journal of Psychiatry, 156, 756-760.

[33] Wilson, S.J., Bell, C., Coupland, N.J. and Nutt, D.J. (2000) Sleep Changes During Long-Term Treatment of Depression with Fluvoxamine-A Home-Based Study. Psychopharmacology, 149, 360-365. http://dx.doi.org/10.1007/s002139900362

[34] Irons, J. (2005) Fluvoxamine in the Treatment of Anxiety Disorders. Neuropsychiatric Disease and Treatment, 1, 289299.

[35] Horii, A., Uno, A., Kitahara, T., Mitani, K., Masumura, C., Kizawa, K., et al. (2007) Effects of Fluvoxamine on Anxiety, Depression, and Subjective Handicaps of Chronic Dizziness Patients with or without Neuro-Otologic Diseases. Journal of Vestibular Research, 17, 1-8. 
[36] Omori, I.M., Watanabe, N., Nakagawa, A., Cipriani, A., Barbui, C., McGuire, H., et al. (2010) Fluvoxamine versus Other Anti-Depressive Agents for Depression. Cochrane Database of Systematic Reviews, 17, Article ID: CD006114. Malik, A.S., Boyko, O., Atkar, N. and Young, W.F. (2001) A Comparative Study of MR Imaging Profile of Titanium Pedicle Screws. Acta Radiologica, 42, 291-293. http://dx.doi.org/10.1080/028418501127346846 